\title{
Smart Phase Change-over system with AT89C52 Microcontroller
}

\author{
Mbaocha Christian \\ Federal University of Technology Owerri \\ Department of Electrical/Electronics Engineering
}

\begin{abstract}
This project is designed to check the availability of any live phase, and the load will be connected to the live phase only. This feat is achieved with AT89C52 MCU. This controller continuosly checks for live condition of all the phases connected to it, and the controller connects the load the load to the active phase Relay, live phase, controller, rectifier, using a relay. The relay is driven with a transistor. If two or three phases are live, the phase will be connected to the phase that is ON only and automatically transferred to the phase that is $O N$ in the event of a main outage or from generator back to main when restored. An LCD is provided to display the status of the phase condition. Conrast control preset is given for LCD contrast control.. Furthermore the project uses a regulated $12 \mathrm{~V}, 500 \mathrm{~mA}$ power supply. Bridge type full-wave rectifier was used to rectify the a.c output of the secondary 230/12V step-down transformer.
\end{abstract}

Key words: Relay, Rectifier, Live phase, contrast control, controller, Comparator

\section{Introduction}

The invention of electricity and its advancements in the field of electrical engineering has made electrical energy so vast in its applications. A modern house today, cannot be said to be one if it has no use for electricity .This is because most of the items required for making life fit and comfortable in a home functions with electricity. Electrical appliances like water heaters, radios, televisions, fans, water pumps e.t.c all have absolute need for electricity.

Unfortunatetly though the poor availability of public utility power in Nigeria has pushed her citizens to seek alternatives and in dependent means of electricity .This has resulted in individuals buying wind turbines,solar panels,generating sets and so on . Unavoidably this requires careful selection of the one to be ON to their use - alternative power or public power utility.

Sequel to this, phase absence is a very common and severe problem in any industry,home or office. Many times one or two phases may not be live in the three phase supply, because of this ;some electrical appliances will be ON in one room and OFF in another room. This project is designed to check the availability of any live phase, and the load will be connected to the live phase only. This feat is achieved with AT89C52 MCU [1]. This controller continuosly checks for live condition of all the phases connected to it, and the controller connects the load the load to the active phaseusing a relay. The relay is driven with a transistor. If two or three phases are live, the phase will be connected to the phase that is ON only and automatically transferred to the phase that is $\mathrm{ON}$ in the event of a main outage or from generator back to main when restored. An LCD is provided to display the status of the phase condition. [2] Conrast control preset is given for LCD contrast control.Furthermore the project uses a regulated 12V,500mApower supply. Bridge type full-wave rectifier was used to rectify the a.c output of the secondary $230 / 12 \mathrm{~V}$ step - down transformer [3].

In addition due to problems incurred over interrupted power supply, this led to the discovery of threephase intelligent switching system which makes the selection process a lot stress free,efficient and cost effectuive.The three-phase intelligent switching system makes our network infrastructure smarter. Intelligent switching systems are in a giving phase in that companies are continually developing solutions that will make network systems smarter in the future [4].

The demand for sensitive systems which are able to monitor the violent and devastating effect of fire and vandals at homes,offices etc have increased. This led to the idea of an intelligent switching system which has the ability to monitor, control and switch between phases. It also provides the comfort of starting a standby generator when there is power faliure from the mains ( $\mathrm{PHCN})$ without the aid of an operator. The switching between the mains and the generator occurs in micro seconds.

\section{Design Methodology and Analysis}

The different modules of three-phase smart switching system are presented here. These include:

\subsection{The Voltage Reference/Comparator Unit}

This is the decision making unit of the system. Sample voltages are compared based on the reference values set. The unit has variable resistor used as potential zener diodes for voltage references, operational amplifiers as voltage comparators and industrial relays for interfacing the D.C outputs with the A.C inputs [5]. 
The voltage reference settings are Zener diode $\mathrm{D}_{13}=3 \mathrm{~V}$, Zener diode $\mathrm{D}_{14} \quad=4.7 \mathrm{~V}$, Zener diode $\mathrm{D}_{15}=10 \mathrm{~V}$, Potentiometer $\mathrm{VR}_{1}=13 \mathrm{~V}$, and the d.c. output from each phase after filtration equals $18 \mathrm{~V}$.

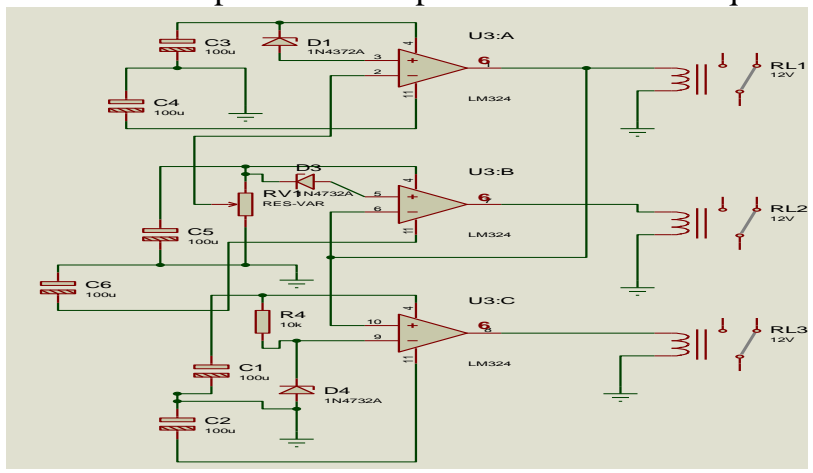

Fig.1: The comparator unit.

In the design, as seen in fig 1 the reference voltage for the IC comparator is from $\mathrm{VR}_{1}$ potentiometer. Once the input source at pin 3 of the IC is greater, a high output is produced at its pin terminal 6 to energize relay $R_{L A}$. The energized relay immediately closes on the phase one supply to the A.C load- Bulb $B_{L}$.

But when phase two has higher voltage than phase one, the reference voltage at pin 2 of $\mathrm{IC}_{1}$ increases to make the operational amplifier go low, and de-energizes relay $\mathrm{R}_{\mathrm{LA}}$. Phase one supply is then shifted to the comparator two i.e. $\mathrm{IC}_{2}$. The reference voltage for $\mathrm{IC}_{2}$ is from the output of $\mathrm{IC}_{1}$. As far as output voltage of $\mathrm{IC}_{1}$ is high, pin 2 terminal of the second comparator will remain greater than the input value at pin 3 of $\mathrm{IC}_{2}$. This will make it impossible for the second relay, $\mathrm{R}_{\mathrm{LB}}$ to be energized. But one, $\mathrm{IC}_{1}$ goes low, voltage at pin 2 of $\mathrm{IC}_{2}$ immediately gets to $\mathrm{OV}$, comparator 2 is pushed to energize relay $\mathrm{R}_{\mathrm{LB}}$. Phase two supply can only be connected to the load when the other two phase are out of supply. Then, the reference of $10 \mathrm{~V}$ from the diode $\mathrm{D}_{15}$ will be at the terminal 3 of $\mathrm{IC}_{3}$. The positive difference resulting from the two inputs of the comparator puts relay $\mathrm{RL}_{\mathrm{C}}$ in active form $[5,6]$.

\subsection{The Inverter Section}

This section changes a low dc voltage to a high ac output, big enough to power the ac load. It has a dc power charging unit that ensures the battery is in top condition $[7,8]$.

As long as there is supply to ac load from the three phases, the battery will be charging. When the phases are off, the battery is switched on to the inverter section to produce the alternative source of energy.

\subsection{The Charging Unit}

This is like the normal power supply that converts high ac input to a low dc output. The unit transform the high ac input to a low one, rectifies it to produce a dc output. A relay is connected in parallel with the dc output to disconnect the battery from the inverter section while it is charging. The values of the components used for the power charging unit are previously calculate The circuit is as shown in fig 2 .

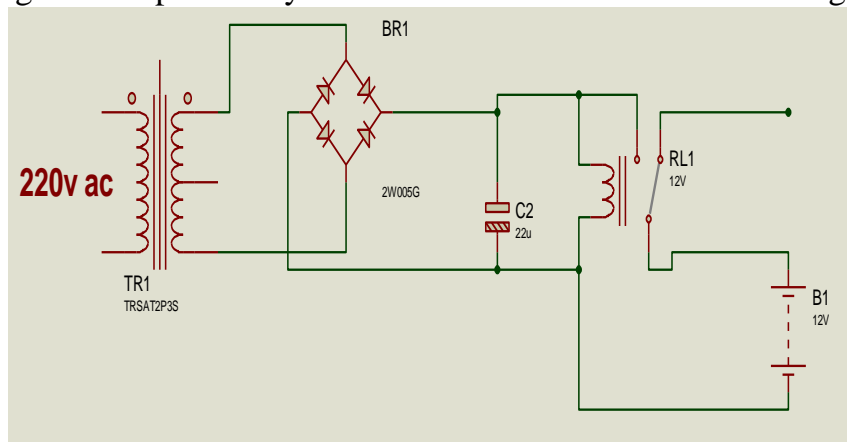

Fig. 2: The circuit diagram of the charging unit

\subsection{The Oscillator Unit}

An oscillator is an electronic circuit that generates electrical waveform even when there is no input of such signal. The circuit builds on the internal disturbances around the active components, sends a part of the output produced to the input section for further amplification. The feedback signal sent is a positive one and in phase with the sample at the input. In this design, however, a digital inverter was applied to produce an inverted output with reference to an input made to it. When the input is high, the output becomes low. Also, when the input is low, the reverse is the case at the output. The digital IC is a hex inverter (CD7404). Only two of such inverters from the I.C were used in producing the alternating signal needed [9].

Suitably, the charging feature of a capacitor helped in bringing out low or high voltage depending on wether it was charging or discharging. Capacitor $\mathrm{C}_{8}$ is charged through the variable resistor (rheostat) $\mathrm{VR}_{2}$ and 
discharged through fixed resistor, $\mathrm{R}_{2}$. This arrangement formed an $\mathrm{R}-\mathrm{C}$ oscillator with its test point voltage connected as input to pin 1 terminal of the HEX inverter. Normally, the high voltage at pin 1 comes out low at pin 2 of the digital inverter. The output of the pi 2 is split into two-one to switch on a transistor while the other is fed back to the input terminal pin 3. Again, a voltage level at the pin 4 terminal will definitely be the opposite of the one at the input terminal, pin 3.

Consequently, with the charging and discharging action of capacitor $\mathrm{C}_{8}$, there will be an alternating signal between pin terminals 2 and 4 . The rate at which the capacitor charges and discharges forms the frequency of the charging outputs of pin 2 and pin 4 . Taking the frequency to be $50 \mathrm{~Hz}$ (i.e. power frequency) and the variable resistor set at $1000 \Omega$. Then, using $\mathrm{T}=0.69 \mathrm{CR}$.

Resistor $\mathrm{R}_{1}$ has to be $1000 \Omega$ in order to maintain uniformity with the charging resistor. The circuit connection of the digital inverter is shown in fig 3



\subsection{Amplifier Unit Of The Inverter}

Fig.3: The connection of the digital hex inverter.

The metal oxide semiconductor field effect transistor (MOSFET) is the amplifier used in this inverter section. It is a type of transistor with very high input impedance. Both transistors, $\mathrm{Q}_{1}$ and $\mathrm{Q}_{2}$ are the enhancement mode of MOSFET. They are positively biased into saturation as amplifiers from the signals produced by the digital inverter, $\mathrm{IC}_{4}$. Resistors $\mathrm{R}_{2}$ and $\mathrm{R}_{3}$ were chosen to be $1 \mathrm{~K} \Omega$ in order to stabilize the biasing current of the transistors. Outputs of these amplifiers are separately connected to the end terminals of a step-up transformer, $\mathrm{T}_{4}$. The connection was made to the primary side with the charging voltage coming high alternatively across both ends of the primary terminals of the transformer. A charging magnetic field would be built and coupled across to the secondary coils of the transformer. Since it is a step-up the transformer and the frequency of oscillation is $50 \mathrm{~Hz}$, a high output voltage of about $220 \mathrm{~V}$ is expected at the secondary terminals which is enough to power the ac load. Fig 4 presents the completed circuit for the hardware section of the device $[10,11,12]$.

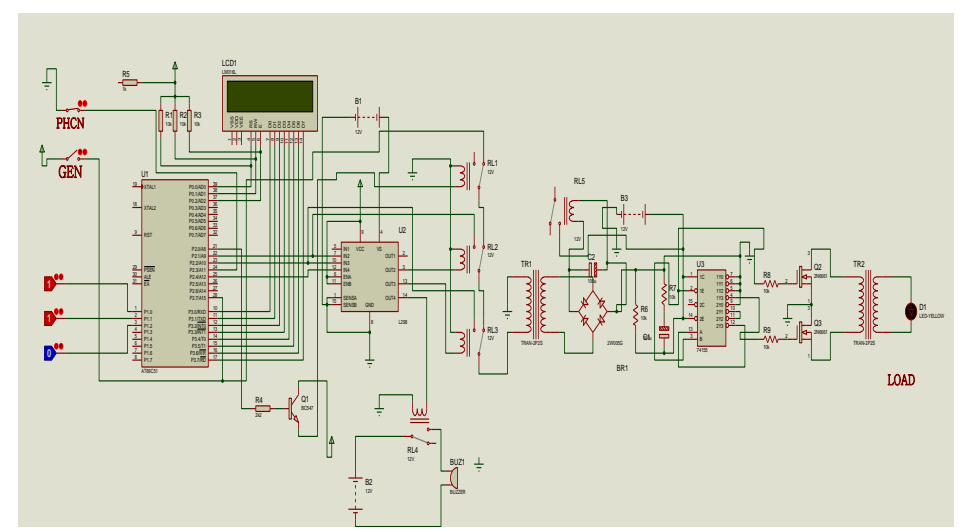

Fig.4 complete circuit diagram.

\section{Simulation/Results}

The simulation of the electronic circuit of the project was done using a software called proteus .The connection was properly made by linking the appriopriate components in the first module as well as the second and third module to produce the general circuit for the design [13]. After the connection, the circuit was simulated and the result displayed in an oscilloscope as well as in the form of bode plot as shown on the test results. Simulation set is shown in fig 5 . 


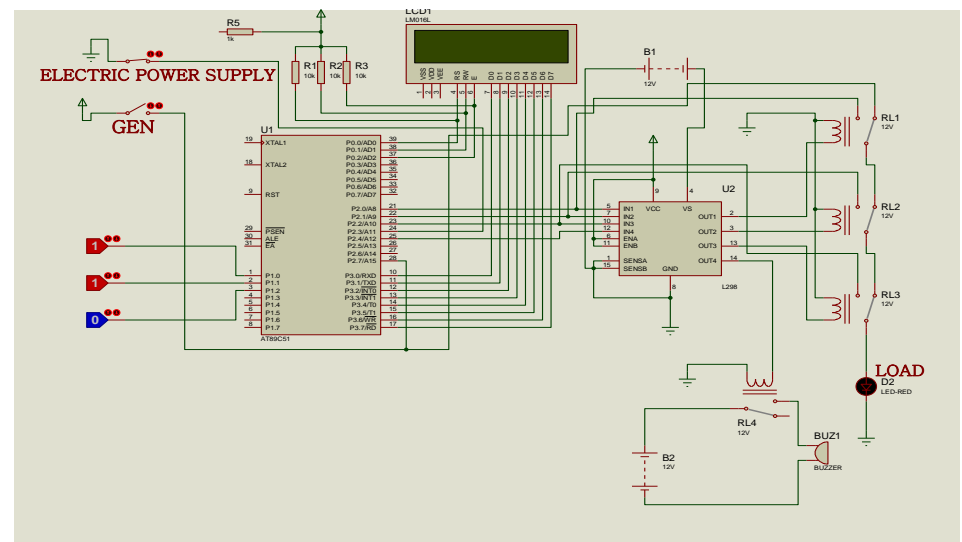

Fig 5: Simulation of completed system using Proetus

\section{Conclusion}

Unfortunatetly though the poor availability of public utility power in the developing countries has pushed her citizens to seek alternatives and dependent means of electricity .This has resulted in individuals buying wind turbines,solar panels,generating sets and so on . Unavoidably this requires careful selection of the one to be $\mathrm{ON}$ to their use - alternative power or public power utility.

Sequel to this, phase absence is a very common and severe problem in any industry,home or office. Many times one or two phases may not be live in the three phase supply, because of this ;some electrical appliances will be ON in one room and OFF in another room. This project is designed to check the availability of any live phase, and the load will be connected to the live phase only. In addition due to problems incirred over interrupted power supply, this led to the discovery of three-phase smart switching system which makes the selection process a lot stress free,efficient and cost effectuive. The three-phase smart switching system makes our network infrastructure smarter. Intelligent switching systems are in a giving phase in that companies are continually developing solutions that will make network systems smarter in the future. The demand for sensitive systems which are able to monitor the violent and devastating effect of fire and vandals at homes,offices etc have increased. This led to the idea of an intelligent switching system which has the ability to monitor, control and switch between phases. It also provides the comfort of starting a standby generator when there is power faliure from the mains $(\mathrm{PHCN})$ without the aid of an operator.The switching between the mains and the generator occurs in micro seconds.

\section{References}

C. N. Gary building A Microcontroller ( E.F.M.Spon Itd,London) 2003.

M. E. Rajash K. E. Malhorta Electronic Projects For The Computer (business bureau, Delhi) 1980

R. J. Maddock,D. M. Calcutt electronics- A Course For Engineers (Longman London.) 1988

F. B. Fredrick, F..C. Robert Solid Atate Devices And Applications ( McGraw Book Company, USA.) 1975

J. E. Angello electronics:FETS,BJTS and Micro-circuits (McGraw Book Company, USA) 1960.

P. J. Hurst Analysis And Design of Analogue Integrated Circuits (Fourth Edition ed. New York) 2001.

7. E. I. Owen Origins of the Inverter (IEEE Industrial application magazine) 1996

8. B. M. Weedy electric Power Systems (Wiley and sons London) 1972.

9. C. I. Daykin Design and Construction of Instrument (Johnes Delhi) 1987

10. J.B. Calvertthree Phase Intelligent ( John Wiley and sons press new york) 2001.

11. R. Edwards Optimizing The Zilog Z8 Forth Microcontoller For Rapid Prototyping (Taylor press USA) 1987.

12. F. I. Radha building Automatic Phase Changer (Chemical press, India) 2002

13. R. M. Norbert Electronic Circuits: Analysis, Simulation And Design (Englewood cliffs new jersey) 1995. 